\title{
Motivation in Learning Physical Education for Junior High School Students in Indonesia
}

\author{
Lutfi Nur*, Adang Suherman, Herman Subarjah, Dian Budiana \\ Sport Education Program, School of Postgraduate Studies \\ Universitas Pendidikan Indonesia \\ Bandung, Indonesia \\ *lutfinur@upi.edu
}

\begin{abstract}
The purpose of this study is to see a picture of the condition of student learning motivation in physical education subjects in junior high school. This study is conducted on junior high school students involved 52 students, consisting of 30 male and 22 female students. A survey is used as the research method. Researchers used physical education learning motivation questionnaire instruments that have been developed and tested with a reliability value of 0.906 which means very high. Motivation level assessment criteria are categorized by using the norm reference evaluation guidelines. The results showed that the overall level of student motivation in taking physical education lessons was in the sufficient category. The details of the results are 1) very high category of $9 \%$; 2) high category of $33 \%$; 3) sufficient category of $33 \%$; 4) low category of $15 \%$; and 5 ) very low category of $10 \%$.
\end{abstract}

Keywords-learning motivation; physical education; middle school students

\section{INTRODUCTION}

Health is a major need for everyone, as well as students. Physical health can be described in a person's physical fitness condition. Unfortunately, the level of fitness among teenagers (students) continues to decline in parallel with increasing rates of obesity among students [1]. The World Health Organization (WHO) identifies physical activity as a public priority to preserve the world of health [2]. Unfortunately, a research has shown that many children's motivation to participate in physical activity during PE continues to decline during the remaining school years [3]. Physical activity is very important for the development of children's health. In this era of information explosion and the rapid advancement of information technology, children have more activities outside physical activity [4]. According to the 2007 Child and Adolescent Health Measurement Initiative [4], 51\% of children aged 6 to 17 years spend more than 1 hour every day on screen-based activities, including watching TV, playing video games, and browsing the Web.

The decrease of physical activity and the level of physical fitness of students can be defined as a form of declining quality of the student's own resources. Lack of physical activity is assumed as a public health problem. Small increases in activity can result in a reduced risk for heart disease, diabetes, osteoporosis and cancer and contribute to loss of muscle mass and increased likelihood of getting injured [2]. There was a dramatic decrease in adolescent physical activity during early adolescence [3]. In children's case, only 30 percent of children and 15 percent of teens get the recommended 60 minutes of physical activity every day [5]. The key to reversing the trend of inactivity of physical activity that is developing among today's teens begins by adjusting attitudes and the environment around physical education [5].

The decline in physical fitness and causes of obesity in school-age children have been associated with reduced motivation for physical activity participation [3]. Motivation is a psychological construct that leads a person in achieving goals and considering the psychological strengths used to strengthen actions [2]. Motivation is a mental process that brings and supports goal-oriented actions. Conceptually, motivation is considered as energy that allows a person to engage in physical or mental actions and in the direction or purpose of actions that are expected to be achieved [6]. Motivation is the heart of many of the most interesting problems of sports, as a result of the development of social environments such as competition, perseverance, learning and performance [6].

Making children to develop and maintain a physically active lifestyle requires children's motivation [4]. Physical education has an important role in the promotion and acquisition of students' healthy behavior [7]. Physical education programs at schools provide a key environment for intervention in developing motoric competencies of school-age children and overall physical fitness, while also stimulating competency motivation to engage in physical activity [3]. Motivation of secondary school students in physical education predicts their motivation, intention, and behavior in the context of free physical activity [8]. Various studies show that students 'motivation in learning physical education plays an important role in understanding the participation of school-age students' physical activity and learning skills in physical education [3]. It is clear that student involvement in physical education classes is influenced and determined by motivational factors [8].

Learning is a multidimensional process that involves various sources of motivation as well as learning physical and sports education [8]. The data shows that children are motivated to do activities, but some cannot motivate themselves to participate in physical activities that improve health [4]. Physical education is one of the most appropriate 
means to promote a healthy lifestyle through physical activity in children. Students' motivation in physical education and sports appears as important variables, because individual students' motivation for physical education has been recognized as a major determinant of students' physical activity [9]. In addition, according to Kretschmann states that the biggest and most significant contribution in social psychology research on physical education over the past 30 years has to do with motivation. Therefore, research on student learning motivation in physical education learning is very important.

\section{LITERATURE REVIEW}

\section{A. Motivation in Learning Physical Education}

Motivation is a psychological phenomenon produced as a result of one's intentions, needs, interests or desires [6]. Motivation is a psychological construct that leads people tin achieving goals and considering the psychological strengths used to strengthen actions [2]. Motivation is a psychological symptom that gives an impulse and strength in doing something. Regarding motivation, one of the most well-known theories is the Self-Determination Theory (SDT) developed by Deci and Ryan. According to this theory motivation is divided into two dimensions: intrinsic and extrinsic motivation [6].

Intrinsic motivation is involvement in activities for pleasure and excitement [10]. Intrinsic motivation is an important factor when associated with physical activity in physical education. Behavior "fun" and tasks will be considered "fun" when associated with increased skills, personal achievement, pleasure, and satisfaction [2]. The result of some research show that students who are more intrinsically motivated have a greater likelihood of practicing outside physical education and sports learning [7]. Individuals are more likely to show adherence to a behavior if they enjoy this behavior (intrinsically motivated) [2]. Intrinsic motivation is closely related to one's own feelings without being influenced by external factors. These feelings can be in the form of comfort, satisfaction, pleasure, joy, and also interest.

Extrinsic motivation is characterized by close identification with social recognition, gifts and rewards [6]. Extrinsic motivation explains how external variables and rewards stimulate the conduct of behavior. Extrinsic motivation can be considered broad in context because it includes social construction. Perceptions of physical activity in physical education, social construction, type of environment, skill requirements for an activity, and type of feedback contribute to participation in engaging in physical activity in physical education [2]. In learning physical education, the application of extrinsic motivation is usually done in the for giving gifts to students or groups of students who can fulfill the learning task well.

Based on the Self-Determination Theory (SDT) theory, it is suggested to promote healthy lifestyles in students by developing intrinsic motivation, not extrinsic. In simple terms, students who want to do physical activity tend to be healthier later on than those who are asked to do physical activity [5]. Motivation is the heart of many of the most interesting problems of sports, as a result of the development of social environments such as competition, perseverance, learning and performance [6]. According to regarding motivation in the field of physical education and sports states that motivation describes one of the most important variables in sports [11]. The statement clarifies the importance of motivation in the field of physical education and sports.

In the practice of physical education and sports, students can engage in motivational factors that encourage or discourage [6]. Children in physical education are often motivated by an opportunity to explore. The child's desire to explore in certain situations and motivates them to be persistent in solving problems, understanding movement skills, and continuing performance [8]. Some studies seem to support that the participation of physical activity in junior high school students is influenced by the experience of students in physical education who have succeeded in motivating students themselves, providing perceptions of competence, and enjoyment [8]. The results showed that students who succeeded in increasing autonomic motivation in physical education, carried out various physical activities during rest periods [8]

\section{METHOD}

This study uses descriptive quantitative methods. In this study, researchers took data, processed data and presented research data with various types of data presentations to provide an overview of a phenomenon and then provide a discussion about the data of the research results. The subjects used in this study were junior high school students with a total of 52 students, consisting of 30 male and 22 female students. The instrument used in the study was a physical education learning motivation questionnaire for junior high school students consisting of 29 statement items. The questionnaire instrument for physical education learning motivation for junior high school students has a validity level of 0.518 and a reliability of 0.906 . The questionnaire grid used in this study is as follows:

TABLE I. QUESTIONNAIRE OF MOTIVATION IN LEARNING PHYSICAL EDUCATION FOR MIDDLE SCHOOL STUDENTS [12]

\begin{tabular}{|ll|c|}
\hline \multicolumn{1}{|c|}{ Aspect } & Total \\
\hline 1. & Perseverance in learning & 7 item \\
\hline 2. & $\begin{array}{l}\text { Resilient in dealing with } \\
\text { difficulties }\end{array}$ & 6 item \\
\hline 3. & $\begin{array}{l}\text { Interest and sharpness of } \\
\text { attention in learning }\end{array}$ & 4 item \\
\hline 4. & $\begin{array}{l}\text { Achieving in learning } \\
\text { activity }\end{array}$ & 5 item \\
\hline 5. & Independent in learning & 29 item \\
\hline \multicolumn{2}{|c|}{ Total } \\
\hline
\end{tabular}

From table 1, there are indicators of motivation questionnaires in physical education learning in middle high schools, which consists of 29 question items divided into 5 indicator aspects. 


\section{RESULT AND DISCUSSION}

The data obtained from the research results through the distribution of questionnaire motivation instrument for physical education learning in the sample has produced data in the form of numbers or scores. The data the researcher presents in several forms of data presentation as follows:

TABLE II. DESCRIPTION OF OVERALL DATA

\begin{tabular}{|c|l|}
\hline Total & 100 \\
\hline Average & 19,31 \\
\hline Standard Deviation & 4,35 \\
\hline Maximum score & 27 \\
\hline Minimum score & 11 \\
\hline
\end{tabular}

Overall, the total score of physical education learning motivation is 1004 , the average is 19.31 , the standard deviation is 4.35 , the maximum score is 27 and minimum score is 11 . Next, the researcher also presents data based on gender:

TABLE III. SUMMARY DATA BASED ON GENDER

\begin{tabular}{|l|l|l|l|}
\hline & \multicolumn{1}{|c|}{ Male } & \multicolumn{1}{|c|}{ Female } & \multicolumn{1}{|c|}{$\begin{array}{c}\text { Total } \\
(\mathbf{M}+\mathbf{F})\end{array}$} \\
\hline Total Sample & 30 & 22 & 52 \\
\hline Total & 617 & 387 & 1004 \\
\hline Average & 20,57 & 17,59 & 19,31 \\
\hline $\begin{array}{l}\text { Standard } \\
\text { Deviation }\end{array}$ & 3,11 & 5,22 & 4,35 \\
\hline $\begin{array}{l}\text { Maximum } \\
\text { score }\end{array}$ & 27 & 27 & 27 \\
\hline $\begin{array}{l}\text { Minimum } \\
\text { score }\end{array}$ & 16 & 11 & 13,5 \\
\hline
\end{tabular}

Based on Table 3. The number of scores obtained from physical education learning motivation in the male sample was 617, on average 20.57, standard deviation 3.11, maximum score 27, minimum score 16. Meanwhile in the sample of women the total score was 387 , on average 17.59, standard deviation of 5.22, maximum score of 27 , minimum score of 11 . Further data description, the researcher presents the data by giving a score category. As for the acquisition category scores for physical education learning motivation of junior high school students are as follows:

TABLE IV. REFERENCE TO SCORE ACHIEVEMENT CATEGORY FOR TEACHING LEARNING MOTIVATION

\begin{tabular}{|l|l|l|}
\hline \multirow{2}{*}{ Vulnerable Score } & \multicolumn{2}{c|}{ Category } \\
\cline { 2 - 3 } & score & \multicolumn{1}{c|}{ Description } \\
\hline Above 25 & A & Very High \\
\hline $21-25$ & B & High \\
\hline $17-20$ & C & Quite High \\
\hline $13-16$ & D & Low \\
\hline Under 13 & E & Very Low \\
\hline
\end{tabular}

Table 4. shows the average overall score with a score of 19.31 in the 'Quite High' category. Based on gender, the male sample obtained an average score of 20.57 in the category of quite high, as well as the average sample score of women with a score of 17.59 in the category of 'Quite High'. Furthermore, the researchers also provided data descriptions based on the frequency of the obtained score, as follows:

TABLE V. FREQUENCY OF ABSOLUTE ACQUISITION SCORE BY $=$ CATEGORY

\begin{tabular}{|l|l|l|l|}
\hline \multicolumn{1}{|c|}{ Category } & Male & Female & $\begin{array}{c}\text { Total } \\
(\mathbf{M}+\mathbf{F})\end{array}$ \\
\hline Very High (A) & 3 & 2 & 5 \\
\hline High (B) & 12 & 5 & 17 \\
\hline Quite High (C) & 13 & 4 & 17 \\
\hline Low (D) & 2 & 6 & 8 \\
\hline Very Low (E) & 0 & 5 & 5 \\
\hline Total & 30 & 22 & 52 \\
\hline
\end{tabular}

The data presentation from previous research has provided a description of the absolute frequency data based on the score category. Next, the researcher also presents a description of the relative frequency data (percentage) based on the score category as follows:

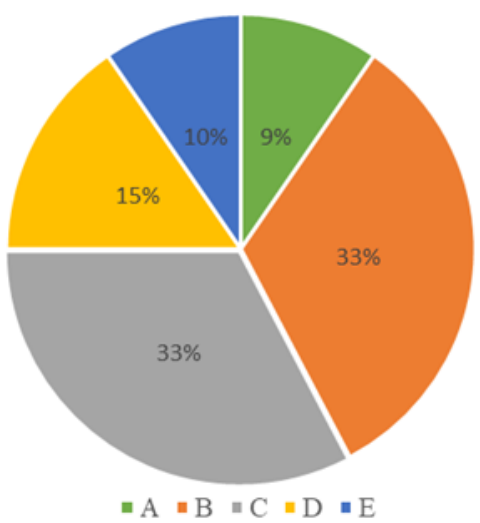

Fig. 1. Relative frequency $(\%)$ overall.

Figure 1 shows the relative frequency (percentage) as a whole, shown that the acquisition of scores that fall into category A (very high) as much as $9 \%$, category B (high) as much as $33 \%$, category $\mathrm{C}$ (quite high) also by $33 \%$, category D (low) by $15 \%$, while category E (very low) by $10 \%$. The highest score category is category B (high) and $\mathrm{C}$ (quite high) with a relative frequency of $33 \%$. Meanwhile the lowest category is category A (very high) as much as $10 \%$. Next the researcher also presents a description of the frequency data related to gender, as follows: 


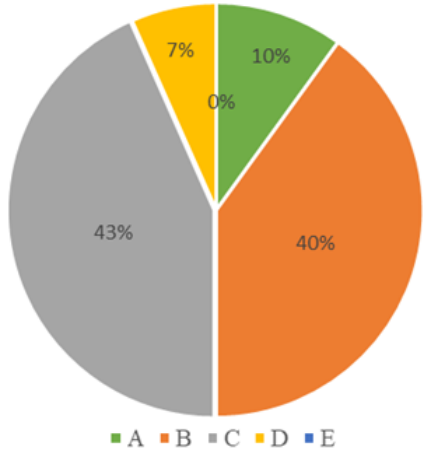

Fig. 2. Relative frequency (\%) of men.

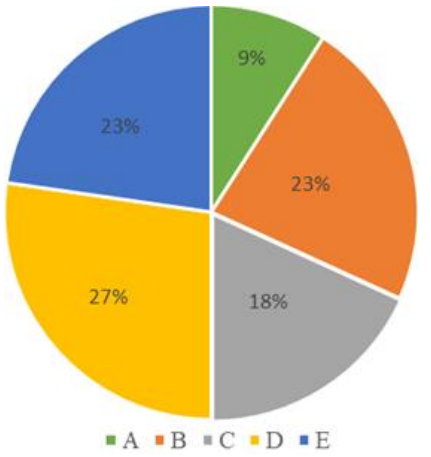

Fig. 3. Relative frequency $(\%)$ of women.

The relative frequency in the sample of men who were in category A (very high) was $10 \%$, category B (high) was $40 \%$, category C (quite high) was $43 \%$, category D (low) was $7 \%$, while category E (high) (very low) of $0 \%$. Whereas for the sample of women the scores obtained in category A (very high) as much as $9 \%$, category $\mathrm{B}$ (high) as much as $23 \%$, category $\mathrm{C}$ (quite high) as much as $18 \%$, category D (low) by $27 \%$, while category E (high) very low) by $23 \%$. On the last presentation of this data description, the researcher gives an overview of the acquisition of the average score based on indicators or aspects of assessment of learning motivation used in the questionnaire motivation learning instrument for physical education in junior high school students.

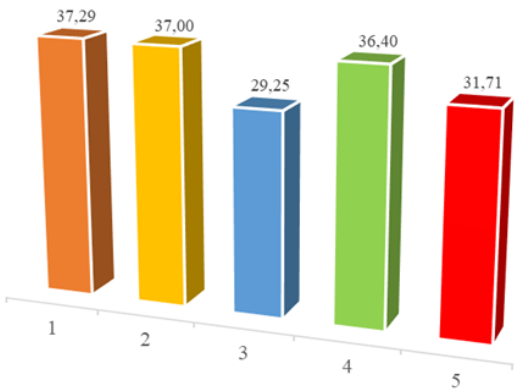

Fig. 4. Average score achievement based on learning motivation aspects.

Figure 4 shows that the average score is based on the assessment aspect of learning motivation with an average score of 37.29 namely aspect 1 (Perseverance in Learning), followed by aspect 2 (Resilient in the Face of Difficulty) with an average score of 37,00 , then with an average score of 36.40 which is aspect 4 (Achievement in Learning), and aspect 5 (Independent in Learning) with an average score of 31.71, and the lowest average score is aspect 3 (Interest and Sharpness in Learning) with an average score of 29.25 .

\section{CONCLUSIONS}

The results of the study showed that on average the overall level of motivation to learn physical education is in the category 'enough'. This shows that the level of junior high school students' motivation for physical education is still not optimal, given the importance of learning motivation in physical education. Several factors can influence the level of motivation of students in physical education.

One of the things that need to be considered is to develop and / or create a conducive environment and in accordance with the level of students' abilities. Presentation of physical activities that are appropriate to students 'level of ability is very important to improve students' learning motivation in physical education. The results of the study report that in junior high school students, the most likely source of motivation in physical education, is students' trust in being able to succeed (do well) in physical education learning [4]. Students who are less skilled physically or cognitively are often awkward and not ready to learn [3]. Taking into account the level of ability of students, they can maintain self-esteem and self-confidence. In physical education, when students have greater self-esteem in their physical abilities, they are more likely to enjoy physical education and want to participate. According to Harter, the development of self-esteem is dependent on two factors [5]. When students have higher self-esteem in terms of their physical abilities, they are more likely to enjoy physical education and want to participate.

The acquisition of scores based on motivational assessment aspects is known that the aspects of interest and sharpness in learning score is the lowest compared to other aspects. This means that learning physical education is still less attractive to some students. It is clear that adults (e.g., teachers, coaches, parents, afterschool program leaders) play a significant role in developing and helping sustain children's physical activity motivation [4]. Obviously, it seems that in this case the role of the teacher is very important. Physical education learning must be more varied, because the same physical education activities can become less attractive from time to time and students do not have meaningful experience from their learning [5]. A teacher must strive to make learning always enjoyable by appreciating group efforts and celebrating individual improvement, physical education becomes a pleasant experience [5].

Physical education learning curriculum factor is, of course, also one of the supporters for teachers to be able to improve student learning motivation. A recent report by the Institute of Medicine reminds us that children's physical activity opportunities and motivation are, in large parts, a policy and school curricular issues [4]. The curriculum policy in schools supports to create and develop a school environment that is filled with physical activity. An environment that is physically active both at school and in the community can help develop, maintain and protect the motivation of children's physical 
activity and also support their academic achievement [4]. An observation shows countries such as Finland, China, Korea or Singapore have excellent academic levels of students, but recent reports show that schools in these countries have implemented physical activity policies that encourage and motivate children to be active physically [4].

Based on the explanation of the result and discussion, this study recommends that in further study, it is needed to be able to increase students' motivation in learning physical education. In addition, some of the factors behind the student's learning motivation really need to be considered and given the right treatment.

Based on the results of research and discussion, the researchers present the conclusions of this study, as follows: a) The level of motivation to learn physical education in junior high school students is in a fairly high category; b) The highest aspect of learning motivation is the aspect of perseverance in learning, while the lowest aspect is the aspect of interest and sharpness in learning.

\section{ACKNOWLEDGMENT}

This research is a collaboration between me and the mentors. I thank Prof. Dr. Adang Suherman, M.A., Prof. Dr. Herman Subarjah, M.Si., and Dr. Dian Budiana, M.Pd., who have provided guidance so that this paper can be completed properly.

\section{REFERENCES}

[1] UNESCO, World-wide Survey of School Physical Education: Final Report 2013. United Nations Educational, Scientific and Cultural Organization: 2013.
[2] M.R. Bice, J.W. Ball, and S. McClaran, "Technology and physical activity motivation". Routledge: International Journal of Sport and Exercise Psychology, 2015.

[3] X. Gu, Y. Chen, A.W. Jacson, and T. Zhang, "Impact of a pedometerbased goal-setting intervention on children's motivation, motor competence, and physical activity in physical education". Routledge: Physical Education and Sport Pedagogy, 2017.

[4] A. Chen, "Top 10 Research Questions Related to Children Physical Activity Motivation". Routledge: Research Quarterly for Exercise and Sport, vol. 84(4), pp. 441-447, 2013.

[5] B. Davies et al., "Intrinsic Motivation in Physical Education". Routledge: Journal of Physical Education, Recreation and Dance, vol. 86(8), pp. 8-13, 2015.

[6] S.A. Cortés et al., "Motivational faktors and effects associated with physical-sport practice in undergraduate students". Elsevier, ScienceDirect: Procedia - Social and Behavioral Sciences, vol. 237, pp. $811-815,2017$.

[7] A. Granero-Gallegos et al., "Importance of Physical Education: motivation and motivational Climate". Elsevier, ScienceDirect: Procedia - Social and Behavioral Sciences, vol. 132, pp. 364-370, 2014.

[8] S. Chen et al., "Relationship Between Motivation and Learning inPhysical Education and After-School Physical Activity". Taylor \& Francis Group: SHAPE America, Research Quarterly for Exercise and Sport, vol. 85, pp. 468-477, 2014.

[9] R. Kretschmann, "Student Motivation In Physical Education - The Evidence In A Nutshell”. Acta Kinesiologica, vol. 8(1), pp. 27-32, 2014.

[10] T. Jaakkola, S. Yli-Piipari, C. Barkoukis, and J. Liukkonena, Relationships among perceived motivational climate, motivational regulations, enjoyment, and PA participation among Finnish physical education students. Routledge: International Journal of Sport and Exercise Psychology, 2015

[11] J.R. Vallerand, "Intrinsic and Extrinsic Motivation in Sport". Encylopedia of Applied Psychology. Elsevier Inc. All Rights Reserved, vol. 2, 2004.

[12] L. Nur, A. Suherman, and H. Subarjah, Validitas dan Reliabilitas Angket Motivasi Belajar Pendidikan Jasmani. Laporan Penelitian. Bandung, 2018. 